\title{
Application for Historical Record of Operation of an Oil Production Treatment Water Filter
}

\author{
Luis F. Hurtado B, Julián R. Camargo L and César A. Perdomo Ch* \\ Universidad Distrital Francisco José de Caldas, Bogotá D.C., Colombia; \\ Ifhurtadob@correo.udistrital.edu.co, jcamargo@udistrital.edu.co,cperdomo@udistrital.edu.co
}

\begin{abstract}
Objectives: This paper shows the development of an application for the historical record of the values with which a wastewater treatment filter operates in the oil industry, used to eliminate traces of oil and solids, and make it suitable in the injection processes or shedding. Methods/Analysis: After analyzing the data, we proceeded to identify the variables within the filter that had to be shown in the program. After that, the programming work was done in the Programmable Logic Controller (PLC) to make this data accessible. The software Microsoft Excel and RSLinx were selected for the final development, the data was communicated from the PLC to this software, and the application was developed, together with its respective simulation and its use was demonstrated in a real case. The entire process is described in this document and, at the academic level; it can be a source of consultation or guidance for the development of applications and subsequent developments. Findings: Process that is automated and therefore uses a PLC (programmable logic controller) for control and operation, together with HMI screens (Human Machine Interface), which make it possible for operators to control and supervise their operation, but do not have software that allow to record its value over time, software that would be useful for field coordinators, maintenance managers and manufacturer representatives, in order to determine efficiency parameters and detect or correct faults. Improvements: The registration can be done to view it via WEB on any device.
\end{abstract}

Keywords: Automated Register, Filters, Human Machine Interface (HMI), Programmable Logic Controller (PLC), Wastewater

\section{Introduction}

One of the sectors that have driven the most economic growth in Colombia has been the oil industry. In the production processes is the treatment of wastewater that is used for the extraction of crude, or for irrigation, or dumping; under the fulfillment of quality conditions ${ }^{1}$.

The most important equipment for the system in question is the plant bed filter, which, due to the number of valves and pumps that it handles, as well as its operation in stages, needs to be automated to achieve a correct operation.
When handling the filter, you must be aware of the behavior of the following variables: inlet manometric pressure and differential pressure input versus output, as they indicate indirectly, if the conditions to perform the work on the machine are appropriate and if the outlet water meets the required requirements.

There are other parameters such as: the accumulated daily time in filtration, or in backwash; the time at rest, the number of working hours of the feeding and fluidization pumps and the air pressure of instruments; all of which is important to estimate production and to develop maintenance plans. 
Even though the numerical value of some of these variables is indicated in the control screen of the device, the periodic record of its values is carried out manually, through tabulation on paper and at certain times of the day. This task must be performed by the plant operator, which entails that:

- By being aware of the operation of the system, neglect the tabulation of the data or vice versa,

- It does not perform the data collection at the precise moment,

- Does not disseminate the obtained data in time to the production and maintenance departments, and

- You cannot perform a quick and accurate analysis of how the equipment is working.

Therefore, there is a need to create an automated registry system that meets the needs of the personnel involved in the operation, maintenance and manufacturing of the filter. This issue is addressed in this work and covers the identification of the specific needs of each group of people involved, the selection of software for the development of the application and the development of it.

\section{Legal Framework on Water Treatment}

For the management and treatment of wastewater in the Colombian territory, there are Decrees 1541 of 1978, 1594 of 1984 and 3930 of 2010, in addition, the Political Constitution of 1991, imposes in its Article 80:

"The State will plan the management and use of natural resources, to guarantee their sustainable development, conservation, restoration or replacement.

In addition, it must prevent and control the environmental deterioration factors, impose the legal sanctions and demand the repair of the damages caused. Like-wise, it will cooperate with other nations in the protection of the ecosystems located in the border areas" 1 .

Colombian legislation requires oil companies to dispose their production waters in an ecological way. These norms are established in decree 1594 of 1984, called Uses of water and liquid waste, which in article 72 provides what is shown in the Table $1 \stackrel{3}{\text {. }}$.

Table 1. Minimum conditions for the dumping of waste water ${ }^{3}$

\begin{tabular}{|c|c|c|}
\hline Reference & Existing user & New user \\
\hline $\mathrm{pH}$ & $5-9$ units & $5-9$ units \\
\hline Temperature & $<40^{\circ} \mathrm{C}$ & $<40^{\circ} \mathrm{C}$ \\
\hline Floating material & No-show & No-show \\
\hline Fats and oils & Removal $>80 \%$ load & Removal $>80 \%$ load \\
\hline Suspended solids & Removal $>50 \%$ load & Removal $>80 \%$ load \\
\hline For domestic waste & O $_{2}$ biochemical demand: & Removal $>80 \%$ load \\
\hline For industrial waste & Removal $>30 \%$ load & Removal $>80 \%$ load \\
\hline
\end{tabular}




\section{Filter Theory}

\subsection{Loose Bed Filters}

There are many filling materials for filters: According to the GPA ${ }^{4}$ among others there are porous ceramic, sand, anthracite (carbon), graphite and others. The filter material must be selected according to the SuspEnded Solids (SES) of the influent. If oil and/or inorganic material are found, the filters tend to fill up.

If sand is used, for example, the oil adheres and must be washed with water and surfactants. Filters filled with walnut shell are currently performing very well. The filters can be designed for surface or deep filtering. In filtering on the surface, the formation of a filter cake on the bed is induced. If the average pore size of the filter is similar to that of the SES, the cake is formed in the first mm. A deep filter is constituted with graded material, in which the average pore size is substantially greater than that of the SES. Fluids enter from the bottom and particles are entrapped throughout the bed 5 .

A graded sand filter (without previous chemicals) can only remove particles up to $10-20 \mu \mathrm{m}$. Smaller ones adhere to each other, agglomerate and cement, eventually channel. For many years, carbon filters (oil-wet) were used to remove suspended oil. Deep bed filtration with walnut shell granules is currently used for AP. the nutshell is preferably water-wet table. The influent (AP) travels from above through the pressure bed causing it to cross the inter-granular micro spaces and remain retained (filters by gravity). The walnut shell provides a very good performance to the filter because it is a coalescer as well as retaining SES in its pores.

Sand filters have historically been used in the "polishing" of river drinking water after treating it with coagulation and flocculation and are used onshore, to filter water. The filters (of walnut shell) are currently used in the "polishing" of the purge water after treating this in the flotation unit with/without flocculants.

\subsection{Description of the Filtration Process}

One of the biggest concerns within the oil industry is to eliminate the traces of oils and solids present in the wastewater, obtained from the entire extraction process, in order to meet state and environmental regulations required for injection or dumping.

The most important equipment used in this process is the filter, which consists of a horizontally arranged tank, which contains in its interior a plant bed composed of walnut shell, which due to its adsorption property, makes the oil particles adhere to it, separating it from water, reaching concentrations of output, less than one part per million.

After the filter has been operating for some time, typically after 12 hours, it is necessary to carry out the bed cleaning, in order to remove the particles of oils and solids that have adhered to it. This process is known as backwash, and is achieved by reversing the flow direction of the water through the equipment, that is, by injecting the water from the bottom, and passing it through a transfer pump, which by the centrifugal action generated makes the oil separates from the bed, and enters a Screen liner system, which is nothing more than a cylindrical mesh, inserted inside the tube that contains it, which allows the bed not to leave the filter and allows the water with the separate oil, go to another equipment, such as a decanter or a tank of waste, which thanks to chemical agents and a time of rest, causes gravitational separation of water and solid oils.

Each filter is composed of six valves with pneumatic actuator operated by solenoid valve, distributed as follows:

- Valve 1. Water inlet to filter,

- Valve 2. Backwash water inlet,

- Valve 3. Backwash water outlet,

- Valve 4. Normalization water outlet,

- Valve 5. Filtered water outlet, and

- Valve 6. Venteo.

Two centrifugal pumps: one for feeding and one for backwash. 


\subsection{Stages of the Process}

\subsubsection{Filtration}

During filtration, valves 1,5 and 6 open, the remaining valves remain closed. The feed pump is in operation and the backwash remains off (Figure 1).

\subsubsection{Backwash, CSP}

Stage that performs a sweep of the stamp chamber of the Backwash pump, valves 1, 5 and 6 remain open. The other valves remain closed. The flow to the filter is normal as in the filtration stage (Figure 2).

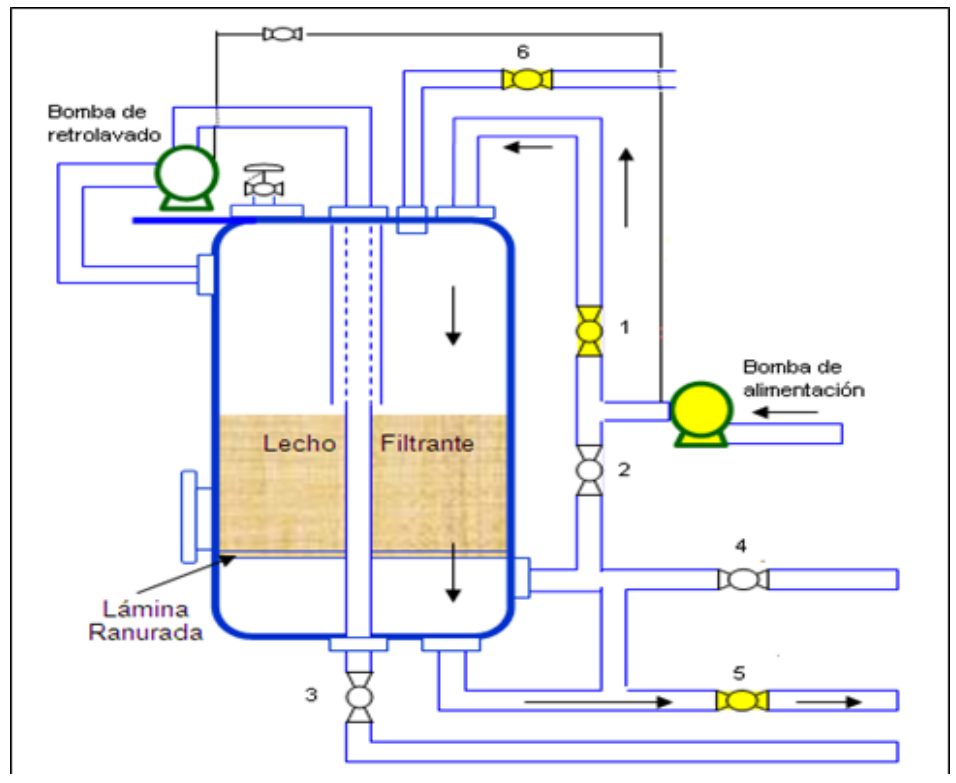

Figure 1. Filtration stage.

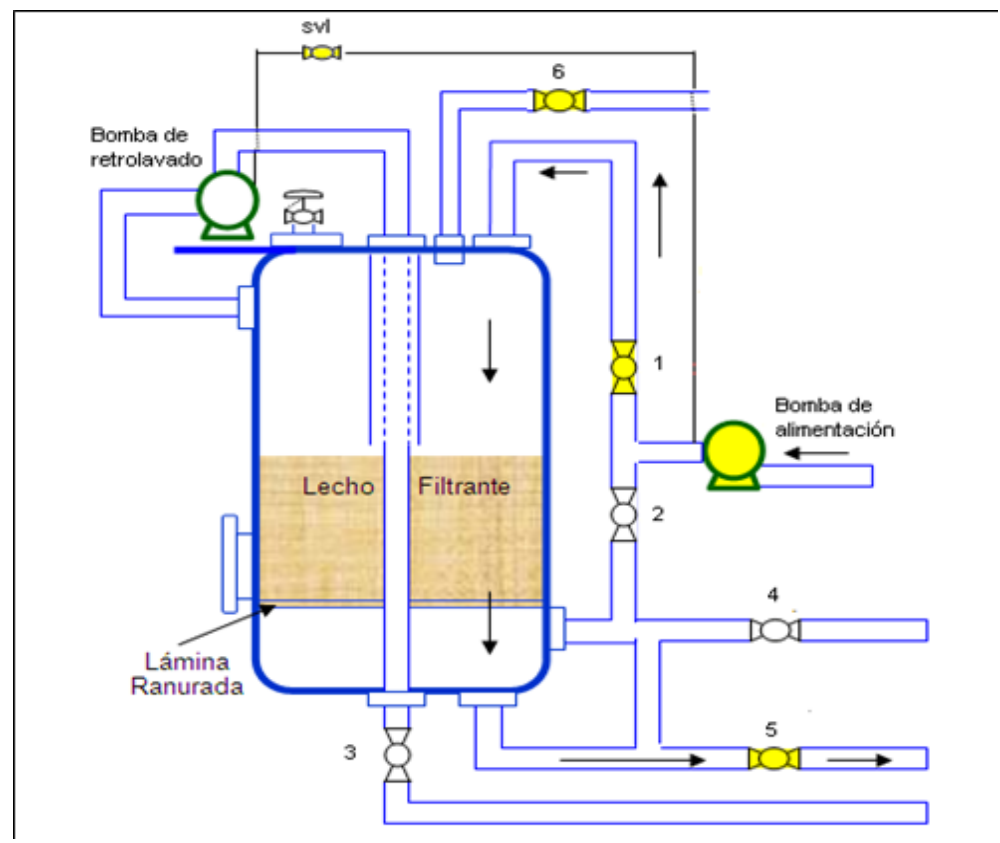

Figure 2. CSP backwashing stage 1. 


\subsubsection{Decompaction}

Stage prepares that the content of the filter for the ignition of the Backwash pump. There is flow through the bottom of the vessel. Valve 2 opens. The other valves remain closed. During this stage there is no flow to the filter only an increase in pressure inside it (Figure 3).

\subsubsection{Fluidization 1}

Stage creates that the path for the bed to be transferred to the Backwash pump. Valve 2 remains open. The other valves remain closed. The Backwash pump is turned on. The typical duration of this stage is 10 seconds (Figure 4).

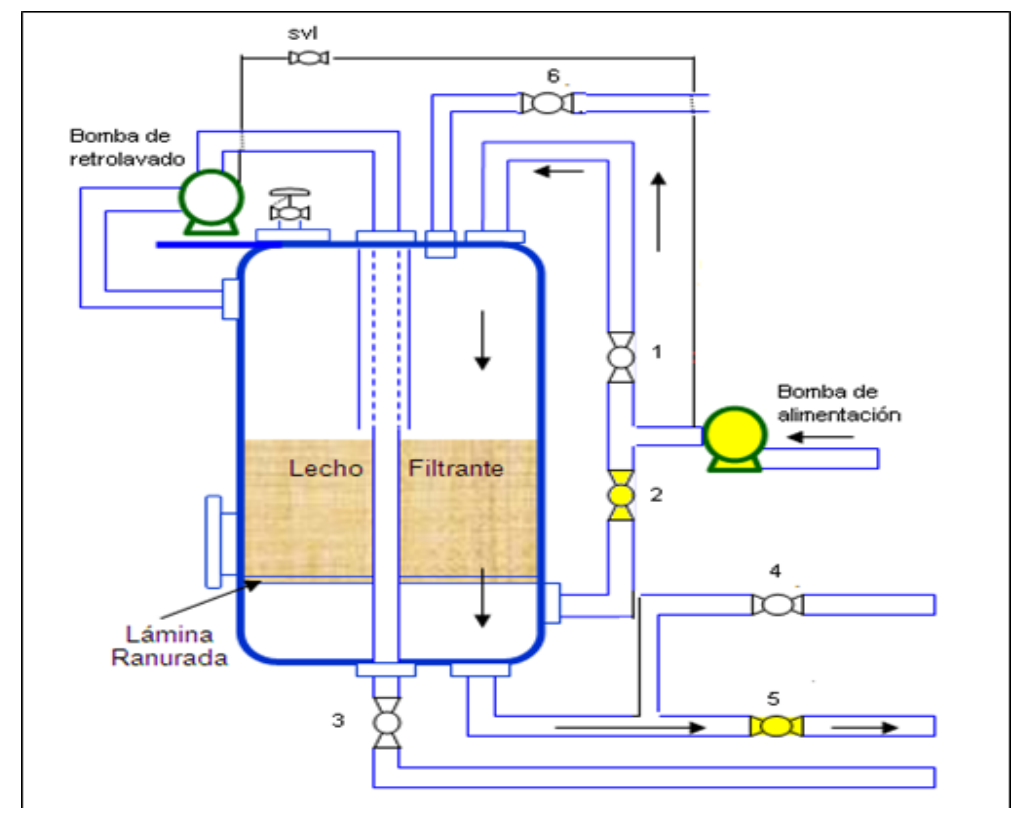

Figure 3. Decompaction stage 2 backwash.

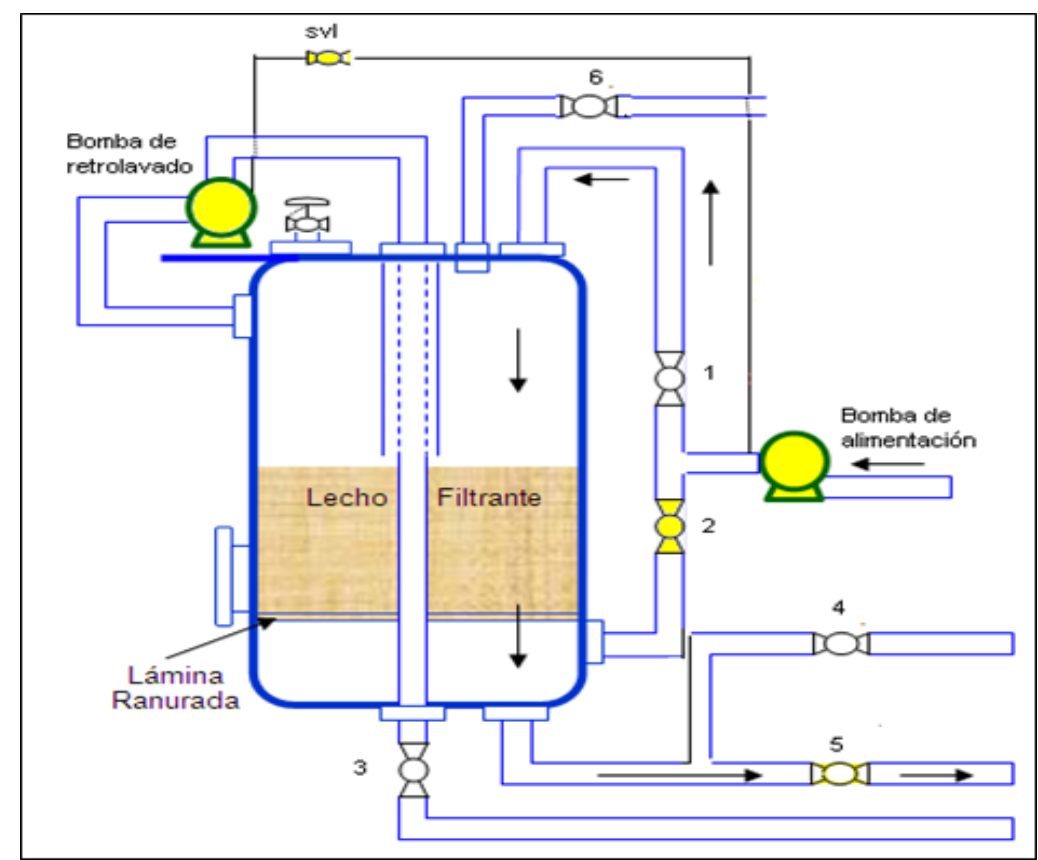

Figure 4. Fluidization 1 stage 3 backwash. 


\subsubsection{Download}

In this period the flow is ascending to remove the filter bed and thus remove solids and oily residues. During this phase, valves 2 and 3 are opened. In addition, the Backwash pump continues working, fulfilling the effect of scrubbing the filter bed (Figure 5).

\subsubsection{Fluidization 2}

Stage seeks that to sweep the solids that could remain in the Backwash pump, or in the lines that connect it. Valve 2 remains open and the Backwash pump is on (Figure 6).

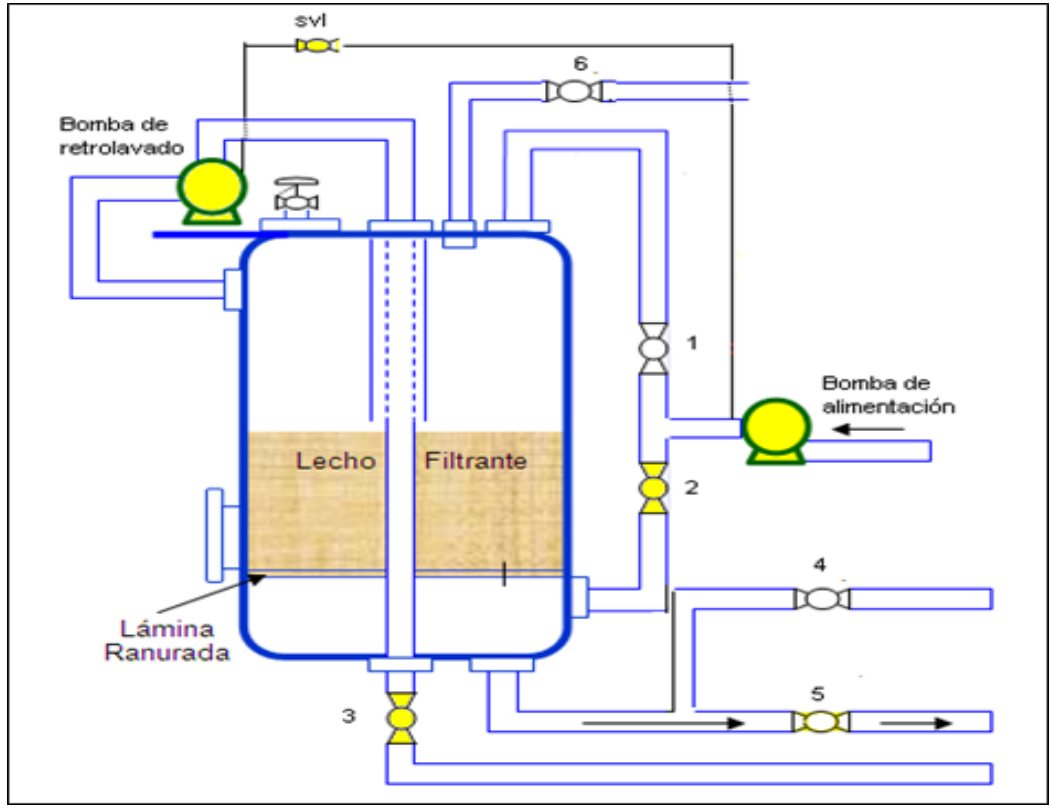

Figure 5. Discharge - backwashing stage 4.

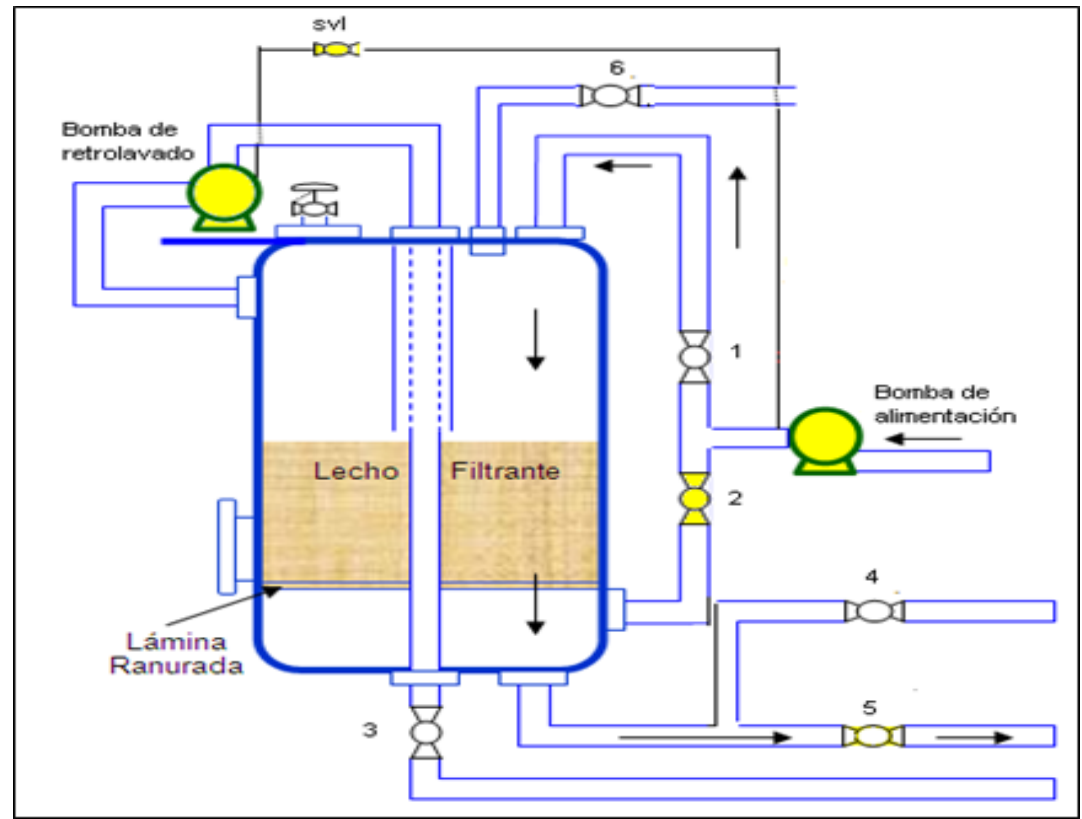

Figure 6. Fluidization 2 stage 5 backwash. 


\subsubsection{Settlement}

Stage pushes that the bed towards the lower slotted sheet, trying to accommodate it again. Valve 1 opens, the other valves remain closed (Figure 7).

\subsubsection{Normalization}

This period corresponds to the final washing of the filter bed. During this phase, the last polluting residues are removed from the bed. Valves 1 and 4 will be open and the others will be closed (Figure 8).

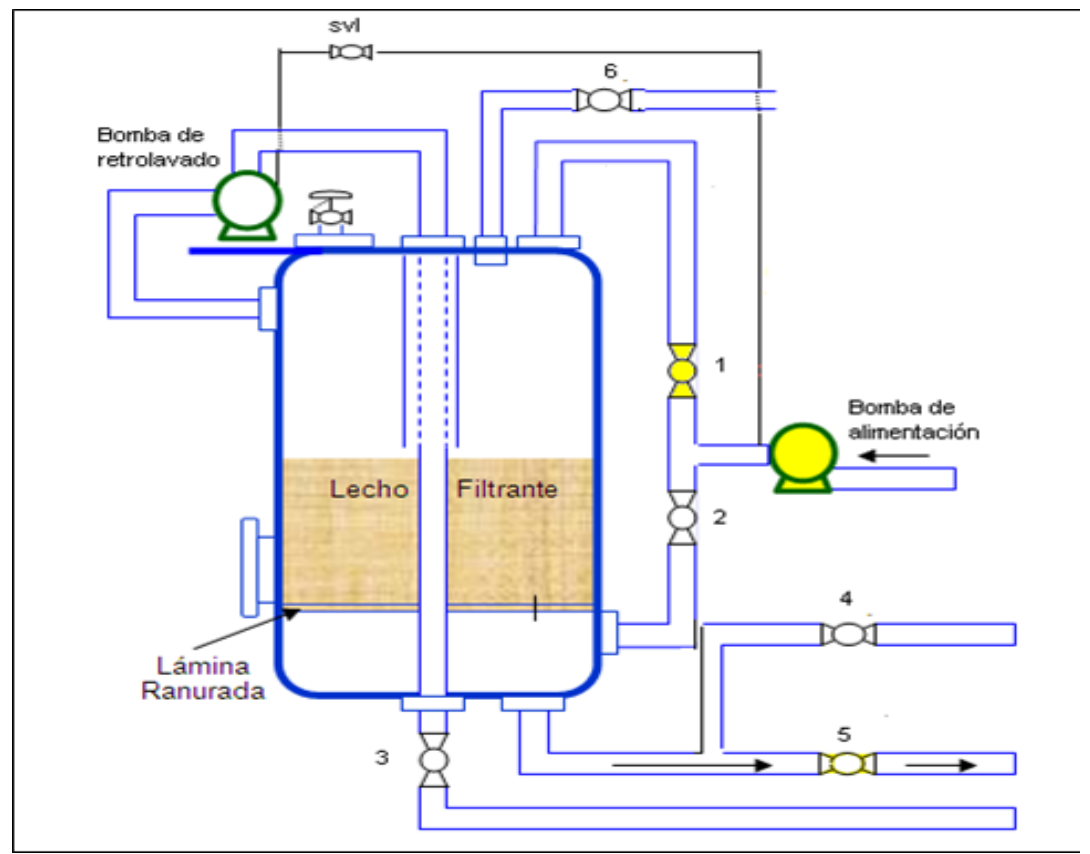

Figure 7. Settlement - backwashing stage 6 .

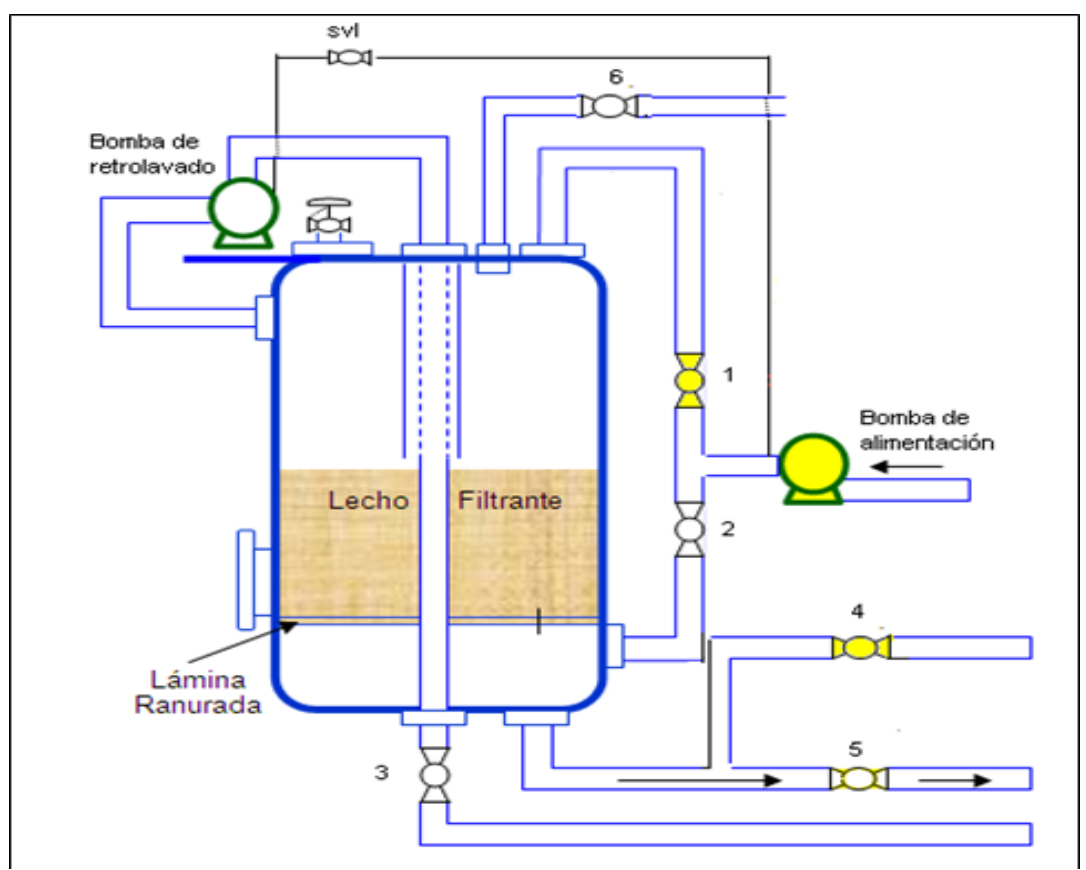

Figure 8. Standardization backwashing stage 7. 


\section{Development of the Application}

\subsection{Identification of the Variables to be Used}

Taking into account the control philosophy for the filtration equipment, it can be identified that the variables that directly intervene in the operation of the equipment are:

\subsubsection{Manometric Pressure of Entrance}

It is the pressure measured in the inlet pipe to the equipment. The equipment must work pressurized for proper operation, and must not exceed 80 PSI to avoid structural damage.

\subsubsection{Differential Pressure}

This variable measures the difference between the inlet manometric pressure and the outlet pressure of the equipment. The importance of this reading is that, indirectly it indicates how saturated the filter bed is. Thus, as this variable increases, the content of oils and solids impregnated in the filter medium also do so.

\subsubsection{Instrument air Pressure}

The instrumentation airline is the source that provides the movement of the actuators responsible for opening the valves that make up the equipment. The minimum pressure so that they can operate correctly is 80 PSI.

\subsubsection{Operating Time in Filtration}

It is important to know the time that the team remained in filtration, since with this data, they can approximate the amount of water treated per day and the impact of this on the process in general.

\subsubsection{Backwashing Time}

It allows estimating the volume of water that must be treated in the mud and cream pools, as well as the amount of chemical inputs that are being used for this purpose.

\subsubsection{Time in Failure}

This variable allows knowing the amount of time, in a day that the equipment remains at rest due to a fault whether, caused by a pressure, a valve, or a motor. This allows the maintenance staff to predict when they should carry out their activities.

\subsubsection{Time Off}

It is the indication of the amount of time, in a day, in which the equipment remains off, without the source of this condition being a failure.

\subsection{Selection of the Software for the Development of the Application}

According to the results obtained in the data analysis and the characteristics of the filters and the operating companies specifically, the following requirements were established:

- Compatibility with the RSlogix 5000 and RSlinx programs, with which the program for the Programmable Logic Controller (PLC) that governs the filter is developed,

- Ease of operation and handling by any person, since operators, coordinators, technicians and maintenance engineers and representatives of the manufacturer can use it,

- Simple adaptability in the way of presenting and organizing the data,

- Exportable and printable, in the case of data and graphics, and

- Low cost in the market.

The options considered for the development of the application, taking into account the previous requirements, were the following: 
- Factory Talk Historian ME de Rockwell automation $^{6}$

- Wonderware Historian ${ }^{\mathrm{z}}$

- MakitronOPC HDA Explorer ${ }^{8}$

- Microsoft Excel

The alternative chosen is the development of the application, using Microsoft Excel software, taking into account that it meets all the requirements exposed at the beginning. In addition, it could be used by a large number of people because it has a low cost, it has the tools to develop programming, and it can directly present the data in its spreadsheets to be disseminated and shared with other users. It has the advantage that it provides the necessary tools to organize and tabulate the data directly in a spreadsheet, which is the task that most operators perform manually, transcribing the data they have collected in the field, and that they record in forms printed.

\subsection{Communication Interfaces}

\subsubsection{Data interface Between Excel and PLC Controllogix}

As fundamental requirements to carry out the application, we have:

- Both devices, both the Ethernet Bridge and the PC must be located within the same Ethernet network,

- The communication between the PLC and the computer equipment must be verified through the Ping instruction,

- The PLC must have loaded and running the control program for the filters, and

- The PC must have Excel installed and the RSLinx Classic software installed?

\subsubsection{Configuration of Communication DDE RSLinx with Excel}

To establish the data communication from the PLC with the Excel, the RSlinx is used as a bridge, which acts as an OPC client to obtain the data from the controller and as a Dinamic Data Exchange (DDE) server that according to ${ }^{10}$ provide the data to Excel. The configuration of all this is done in a simple way, by means of the configuration of a DDE topic shown in Figure 9.

\subsection{The Application}

Routines for managing the operation times in filtration, backwash, failure and shutdown during each day; they were developed based on the TOTalizer (TOT) function, within the set of functions of the RSLogix 5000 PLC programming software; which functions as an integrator of the input signal (Figure 10).

Because Microsoft Excel was chosen, for the development of the application, due to the advantages it offers for the organization of data histories, a programming based on macros developed in VBA language is made ${ }^{11}$. Figure 11 shows the flow diagram with the logic used to develop the application.

\section{Results}

To verify the functionality of the program, it was tested in a real case; in the start-up of a treatment filter of 50KWPD (Kilo barrels of water per day). In the Figure 12 you can see a real image of the used filter.

In the Figure 13 you can see the final result of the application implemented to make the operation record of the water treatment filter.

The history was recorded in the field for an approximate time of 6 hours, recording the inlet pressure, differential pressure and instrument air pressure, verifying the correct data record; this can be seen in Figures 14-16. 


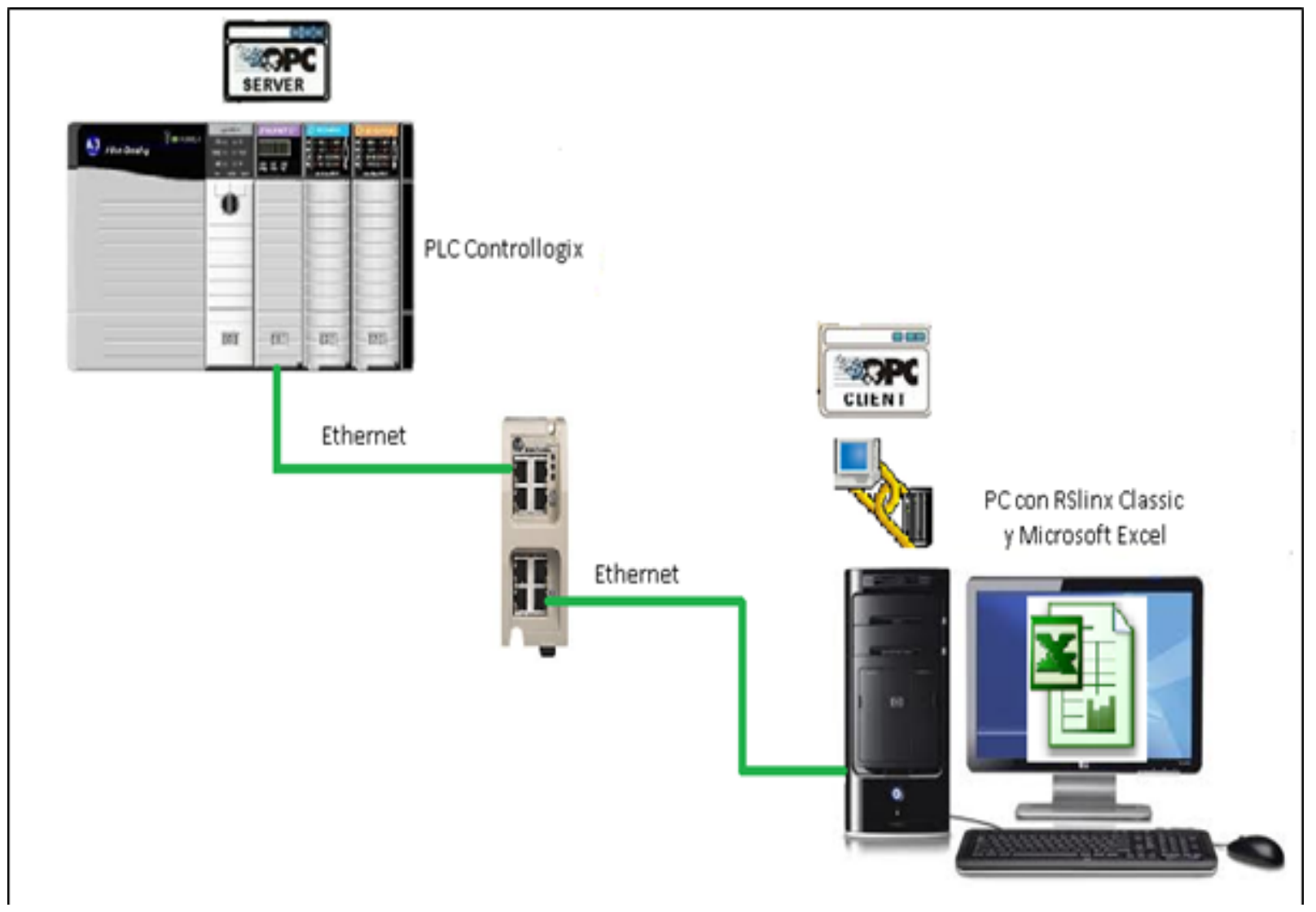

Figure 9. System topology.

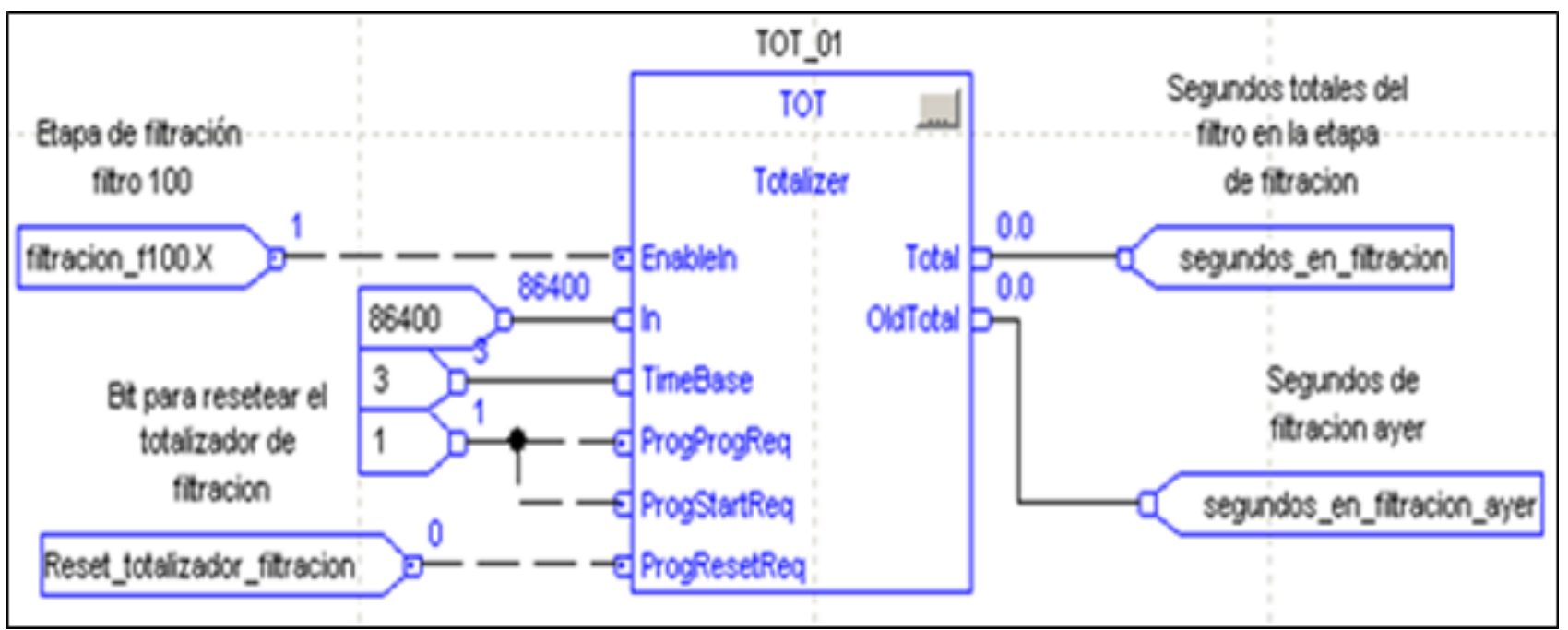

Figure 10. Totalizer function setting. 


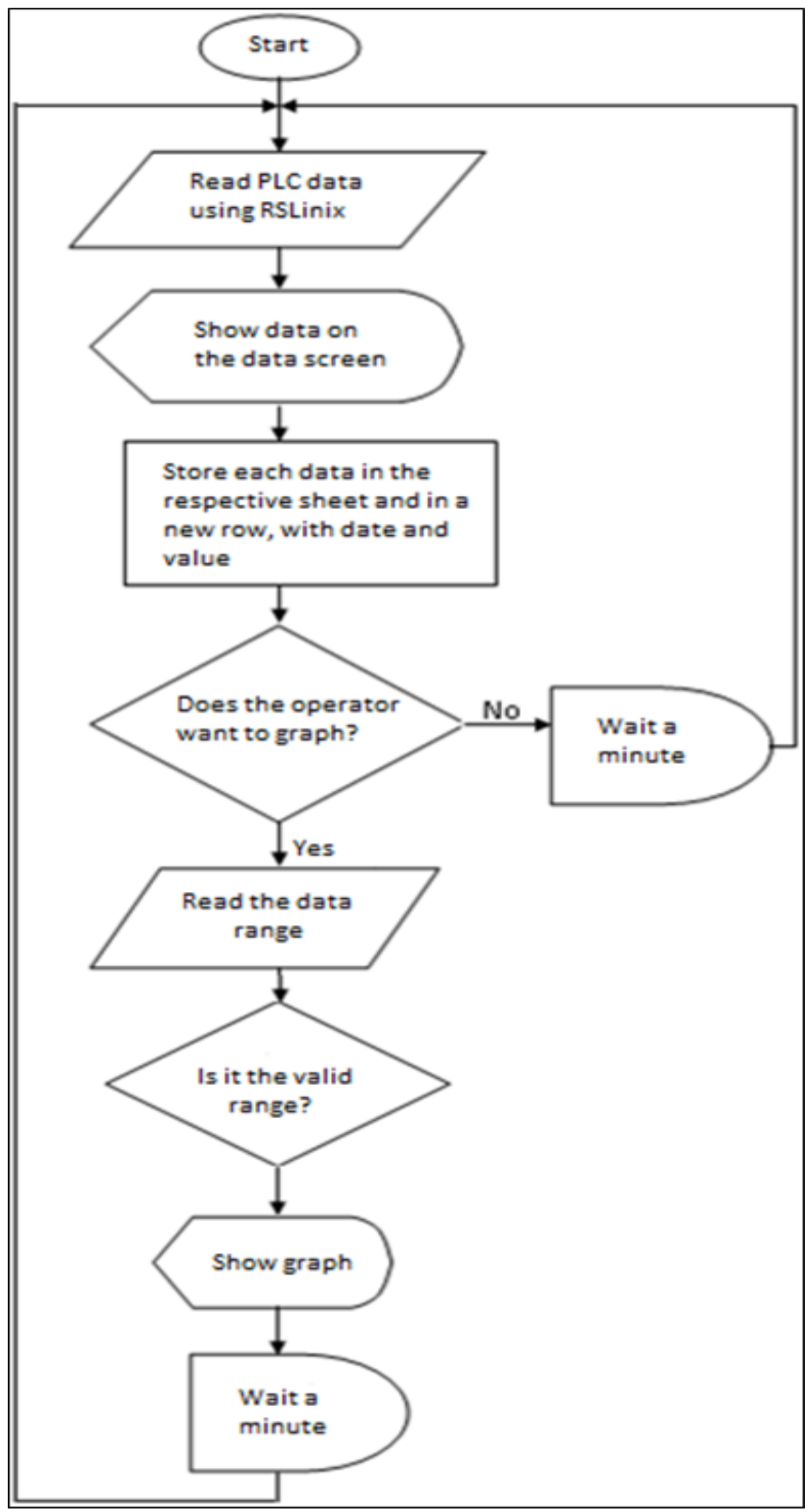

Figure 11. Flow diagram with the logic used to develop the application. 


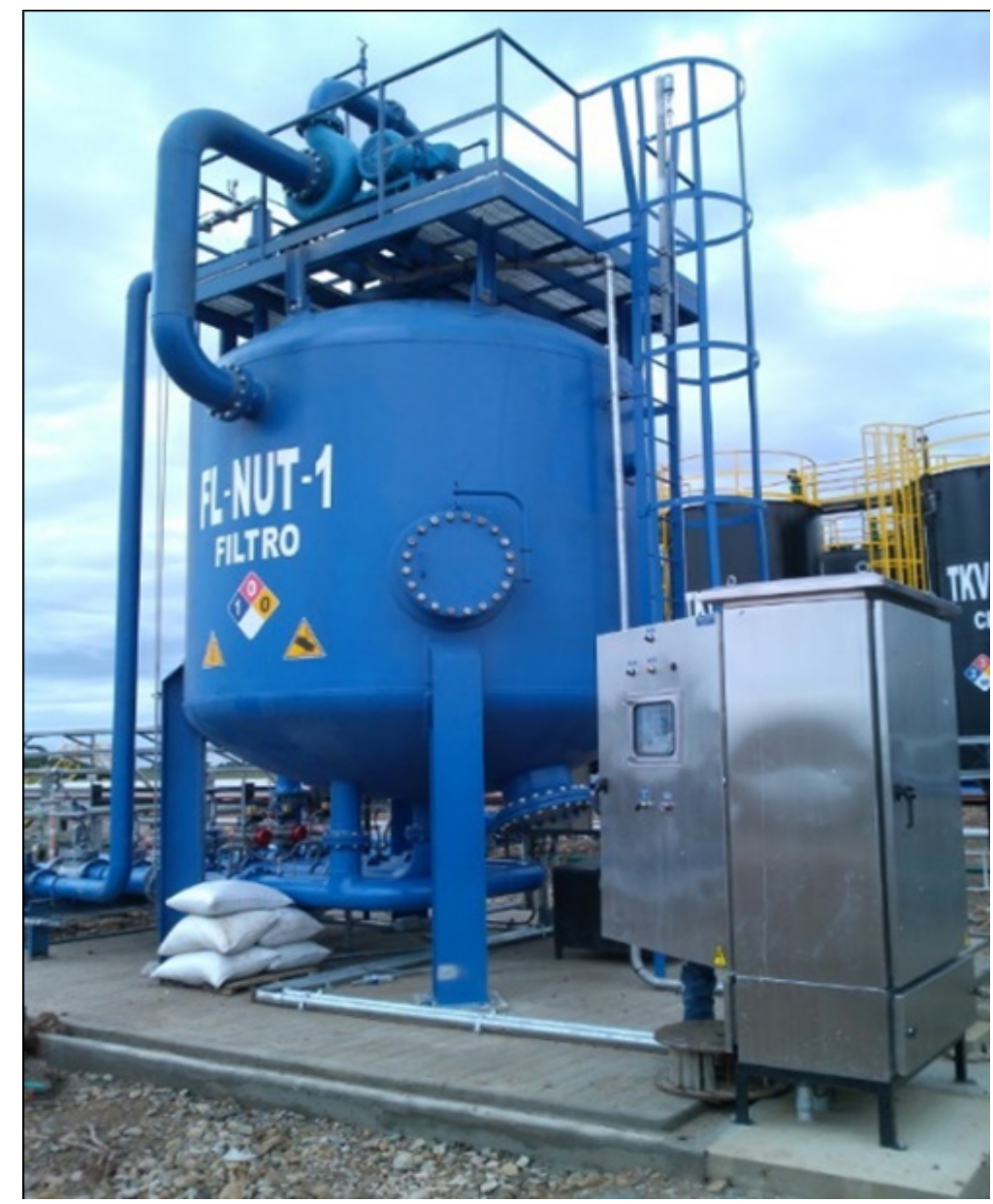

Figure 12. Real image of the used filter.

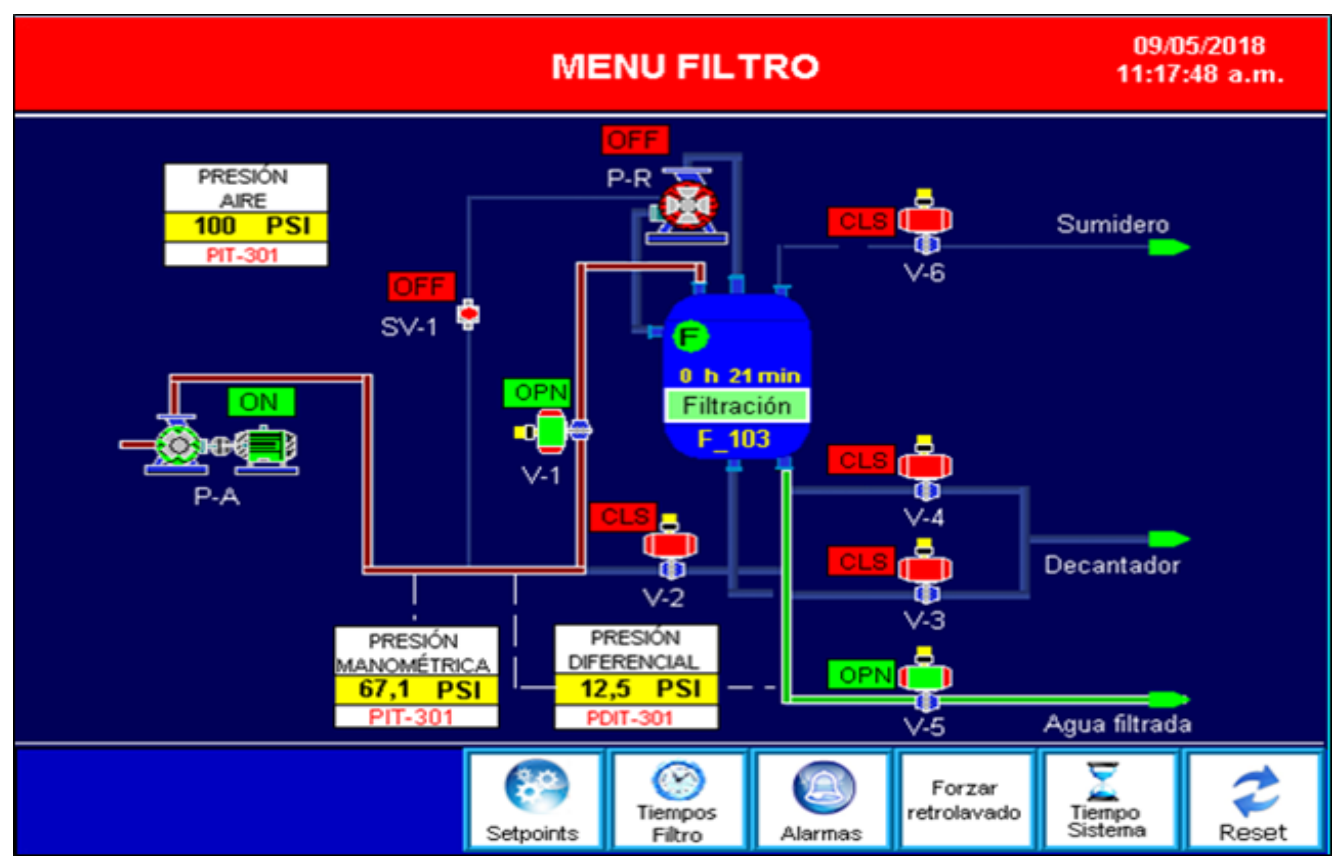

Figure 13. On-site application test details. 


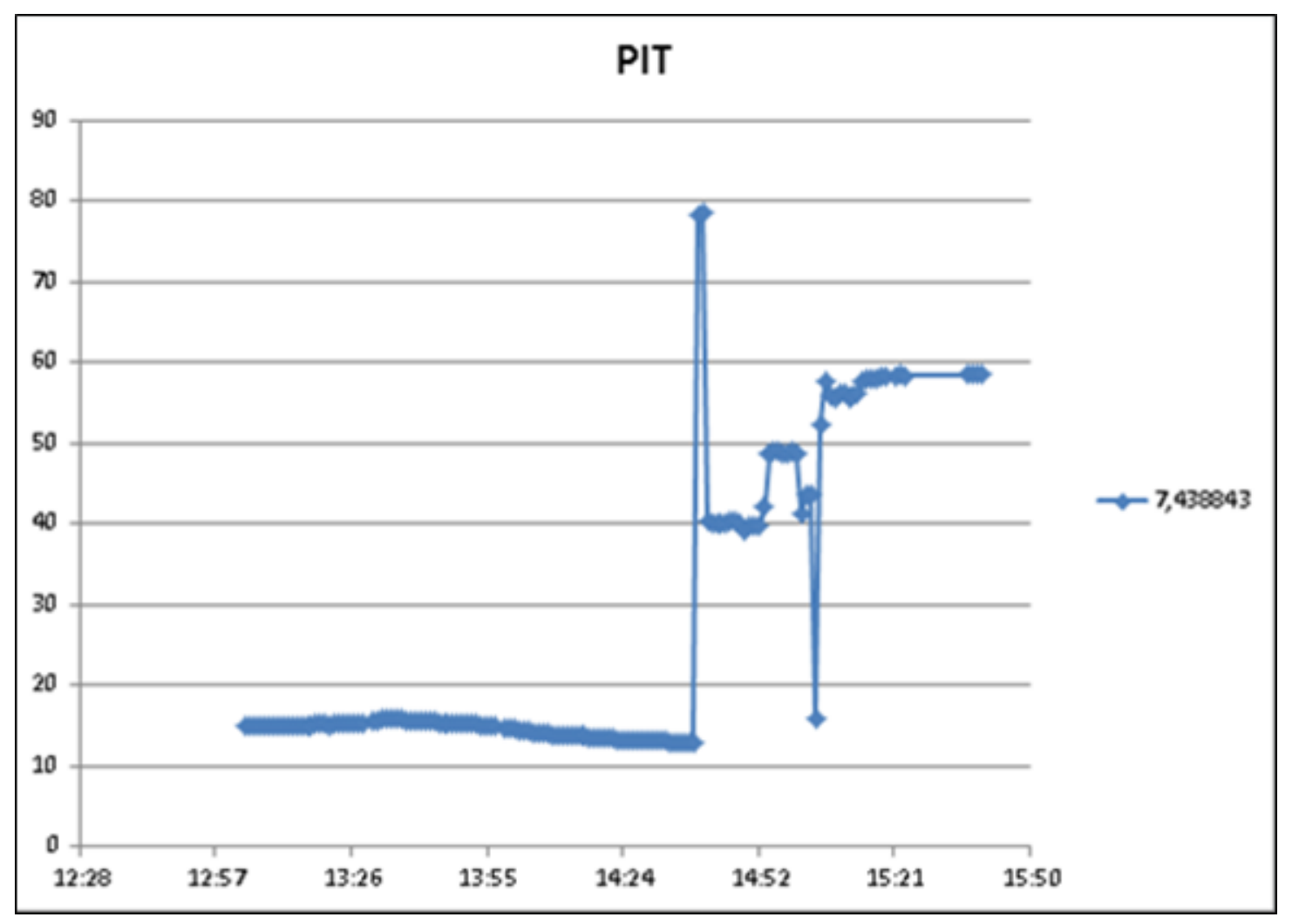

Figure 14. Record for manometric pressure.

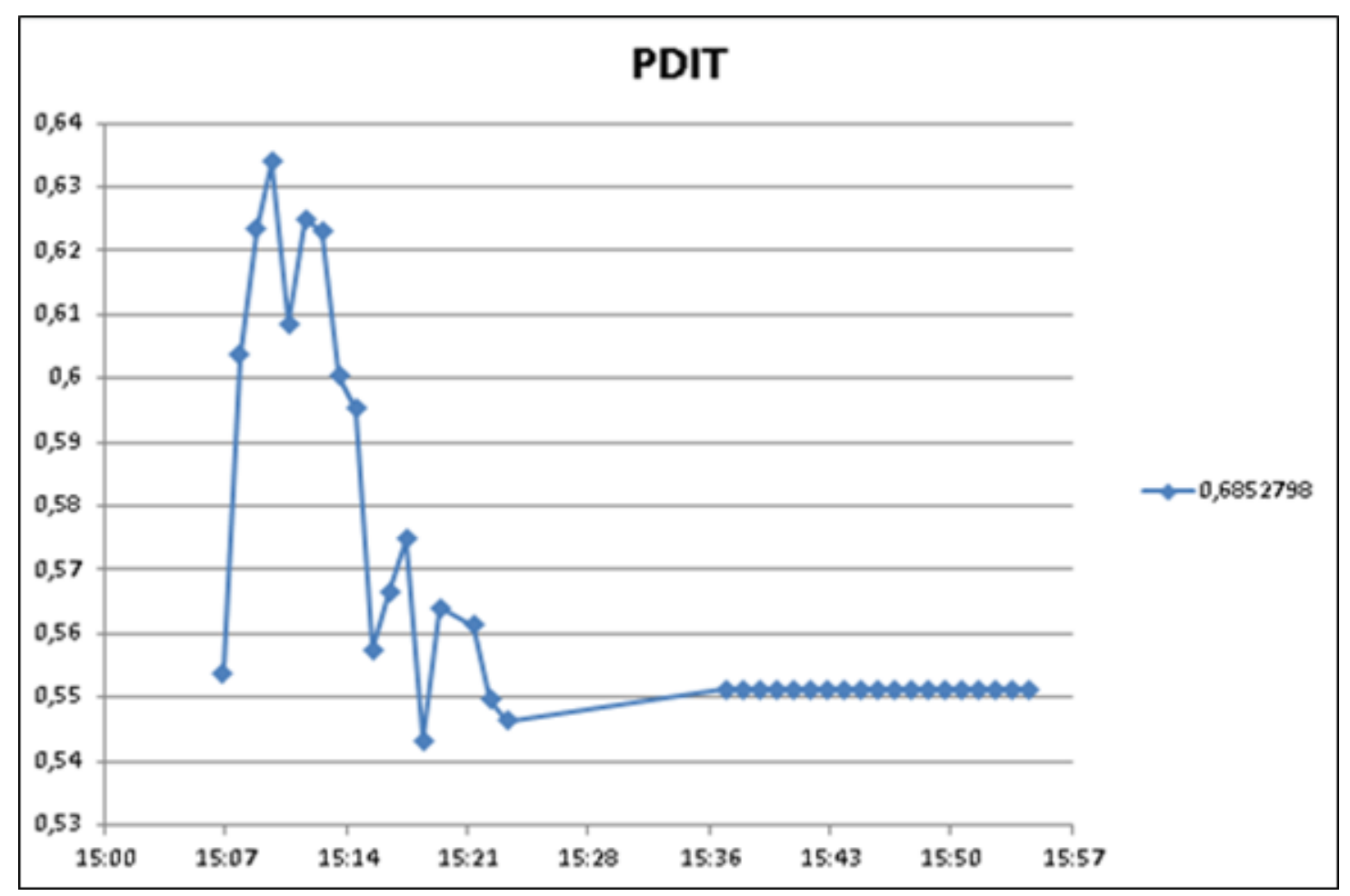

Figure 15. Registration for differential pressure. 


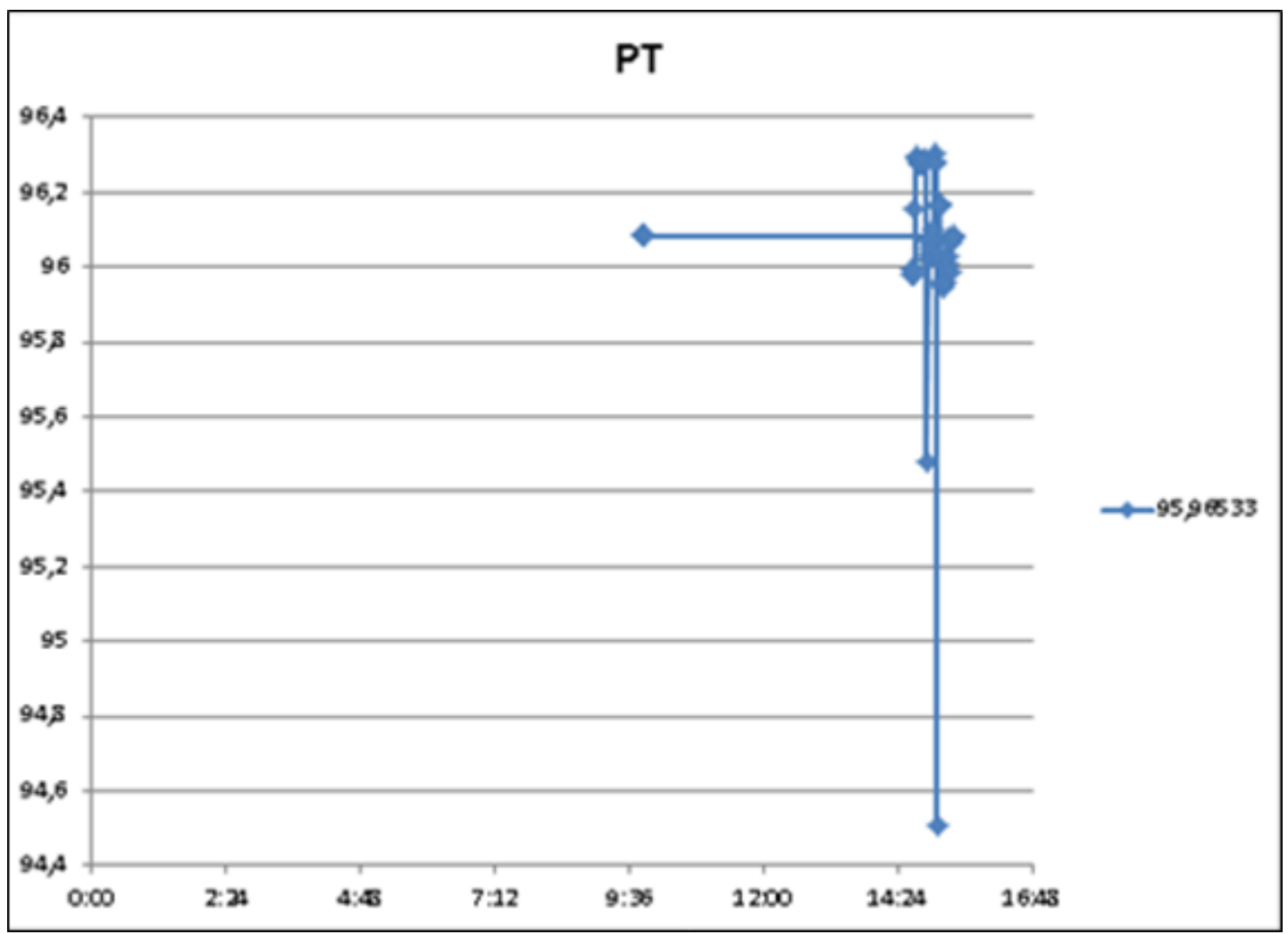

Figure 16. Record for air pressure of instruments.

\section{Conclusions}

The automated registration application makes the data processing of registration and control activities faster, more efficient and more precise, which will facilitate each and every one of the activities of each operation and maintenance department.

The variables that were to be recorded were determined and then the software analysis was done, as well as the application and development of each stage of the program, for the start-up of the same, verifying the programming routines needed in the PLC, deployed in each time and stage, with which it is possible to process and generate the registry of the different variables and the historical, thus achieving the proposed objectives.

The parameters of the daily time taken by the filtration, Backwash, the time at rest, the number of hours of the feeding and fluidization pumps, together with the air pressure of instruments, were taken into account in order to finalize the application and automate the information regarding the filtration of production waters in oil companies.

\section{References}

1. Jaimes DM, Pico MI. Dise-o de la planta de tratamiento de aguas residuales y de producción evaluando las diferentes alternativas nacionales y extranjeras, aplicación campo Colorado. Universidad Industrial de Santander (UIS); 2009. p. 1-228.

2. Esta versión corresponde a la segunda edición corregida de la Constitución Política de Colombia. Constitución Política de Colombia de 1991. Date accessed: 20/07/1991. http:// www.secretariasenado.gov.co/senado/basedoc/constitucion_politica_1991.html.

3. DECRETO 1594 DE 1984. Usos del agua y residuos líquidos. Date accessed: 26/06/1984. http://www.ideam.gov.co/ documents/24024/36843/Dec_1594_1984.pdf/aacbcd5dfed8-4273-9db7-221d291b657f. 
4. GPA. Estudios y Servicios Petroleros S.R.L. Nota Técnica N o 52. Tratamiento De Agua De Purga. Buenos Aires; 2010. p. 1-9.

5. Rodríguez A, Letón A. Tratamientos avanzados de aguas residuales industriales. Informe de vigilancia tecnológica de la Universidad de Alcalá del Círculo de Innovación en Tecnologías Medioambientales y Energía (CITME), Espa-a; 2006. p. 7-9. PMCid: PMC1513582.

6. Olarte J, Rodríguez A.Dise-o E Implementación Del Sistema Scada Factory Talk View De Allen Bradleya Una Maquina Prototipo De Embalaje En El Laboratorio De Automatización De Procesos De La Universidad Pontificia Bolvariana. Universidad Pontificia Bolivarianaescuela De Ingeniería; 2011. p. 1-240. PMid: 21553545.
7. Wonderware. Wonderware Historian sin datosdesaprovechados; 2018.

8. MatrikonOPC. MatrikonOPC: Lista de ProductosInterempresas. The Industrial Connectivity Experts; 2015. p. 1-6.

9. Rockwell Automation. Date accessed: 19/08/2018. https:// en.wikipedia.org/wiki/Rockwell_Automation.

10. Alves R, Normey J, Merino A, Prada C. OPC based distributed real time simulation of complex continuous processes, Simulation Modelling Practice and Theory. 2005; 13:52549.

11. Foxall J. VISUAL BASIC 2012: Paso a paso. Anaya Multimedia; 2006. 